\title{
Evaluation of the PEPFAR/USAID Asibonisane Community Responses Program in KwaZulu-Natal, South Africa
}

Project SOAR

Follow this and additional works at: https://knowledgecommons.popcouncil.org/departments_sbsr-hiv

Part of the Demography, Population, and Ecology Commons, Family, Life Course, and Society Commons, International Public Health Commons, and the Medicine and Health Commons How does access to this work benefit you? Let us know!

\section{Recommended Citation}

Project SOAR. 2017. "Evaluation of the PEPFAR/USAID Asibonisane Community Responses Program in KwaZulu-Natal, South Africa," Activity brief. Washington, DC: Population Council. 


\section{Evaluation of the PEPFAR/USAID Asibonisane Community Responses Program in KwaZulu-Natal, South Africa}

In South Africa's informal settlements residents build communities of improvised housing as they seek employment in the surrounding area. While many are recent migrants, some people live their entire lives in these communities. It is estimated that nearly 400,000 people live in informal settlements in KwaZulu Natal province alone $^{1}$. Since the settlements are unplanned, they are often underserved by municipal services and lack accessible healthcare. Limited educational opportunities coupled with frequent unemployment can create an environment that leads to increased risks for HIV and sexual and gender-based violence (SGBV). Few programs intended to improve HIV outcomes or modulate gender norms have been rigorously evaluated, and there is limited evidence on how to implement large-scale HIV-prevention programming in these contexts.

Project SOAR and partners are addressing these knowledge gaps by conducting an evaluation of the PEPFAR/USAID funded Asibonisane

Research Partners: MatCH Research Unit (Mags Beksinska) and Project SOAR (Paul Hewett, Stephanie Psaki and Julie Pulerwitz)

Location: eThekwini and Ugu Districts in KwaZulu-Natal Province

Study Duration: 2016-2019

For more information, contact Stephanie Psaki (spsaki@ popcouncil.org).

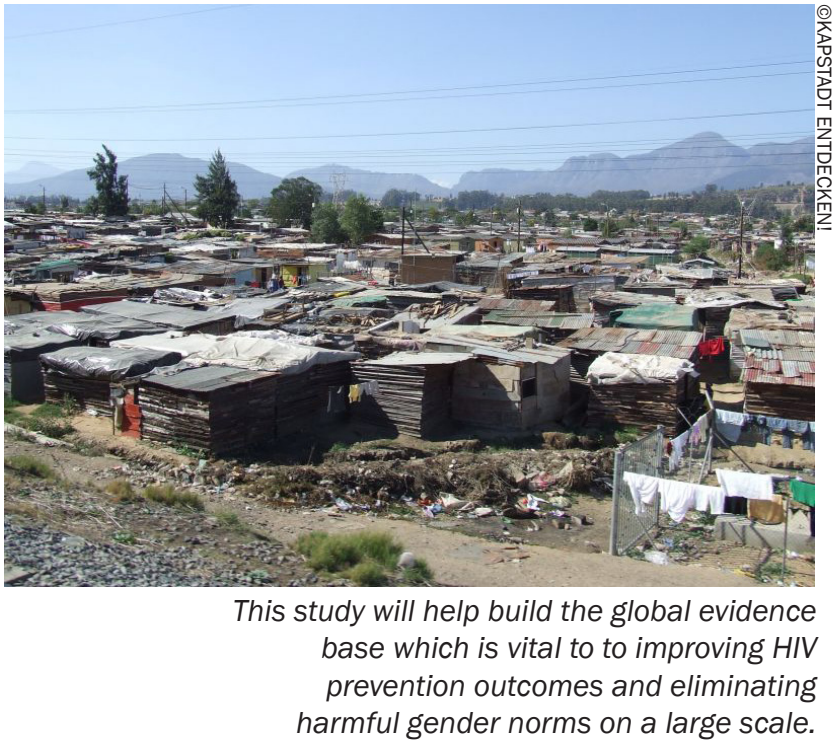

Community Responses (CR) Program in South Africa. Specifically, the study will assess the effectiveness of this community-based HIV prevention program in informal settlements throughout KwaZulu-Natal-one of four provinces where the program is being carried out. The CR intervention is a multifaceted behavior change intervention using an adapted and scaled version of Stepping Stones. The intervention is designed to promote uptake of HIV and SGBV support services, while also promoting equitable gender norms and a positive enabling environment. The program targets young men and women. The Project SOAR evaluation will address a series of important research questions, such as what are the key factors within the informal settlement context that lead to HIV risk behaviors, what level of exposure to an intervention (dose) is needed to improve key outcomes, and how to best scale up group education models such as Stepping Stones. 


\section{What is the Community Responses Program?}

USAID/South Africa is supporting the five-year (2014-2019) Asibonisane CR program implemented by the Centre for Communication Impact. The program's target population is adolescent and adult men and women living in informal settlements in communities within the Gauteng, Kwazulu-Natal, Western Cape, and Mpumalanga provinces.

\section{Key Study Outcomes}

Project SOAR is evaluating several key outcomes that reflect CR program priorities, including:

- Uptake of HIV services (e.g., HIV testing services, care and treatment services).

- Risky sexual behaviors (e.g., increase in consistent condom use).

- Experience/perpetration of SGBV.

- Support for harmful gender norms (as measured by the gender equitable men [GEM] scale).

\section{Research Utilization}

is vital to improving outcomes related to HIV prevention and eliminating harmful gender norms and SGBV, especially in informal settlements. These findings will be particularly relevant for South Africa, given its generalized HIV epidemic and high levels of reported SGBV.

\section{Our Research}

This study uses a cluster stepped-wedge evaluation design whereby 18 clusters (communities) are randomized to when they initiate the CR intervention. A cohort of men (aged 18-35) and women (aged 18-24) in evaluation communities will be followed over the course of approximately 30 months. Survey interviews will be completed at baseline and at three additional time points at 10-month intervals. We will supplement this information with an analysis of district health information system data, indicating trends in service utilization and risk/ prevention behaviors, where feasible.

In addition, we will conduct qualitative interviews with program implementers and a selection of study participants to gain a deeper understanding of the process, experiences, challenges, and benefits of adapting and scaling up the Stepping Stones intervention.
This study aims to influence the achievement of two key objectives of the South Africa's National Strategic Plan on HIV-addressing social and structural drivers of HIV and reaching all vulnerable populations with comprehensive services and interventions. To ensure research utilization of findings, the study team continuously engages with key local stakeholders at all stages of the study from inception to dissemination of findings, including the HIV prevention unit of the Department of Health in KwaZulu-Natal Province and nationally; implementers of community-based HIV activities, such as Centre for Communication Impact; and researchers at universities and institutes.

\footnotetext{
${ }^{1}$ The Housing Development Agency (HDA). 2013. KwaZulu-Natal: Informal settlements Status (2013), HDA Johannesburg, South Africa. https://www.thehda.co.za/ uploads/files/HDA_KwaZulu-Natal_Report_Ir.pdf
}

Project SOAR/Population Council

4301 Connecticut Avenue, NW, Suite 280

Washington, DC 20008

Tel: +12022379400

e-mail: ProjectSOAR@popcouncil.org

popcouncil.org/ProjectSOAR

(c)Population Council, May 2017 